\title{
Chemorheological Study on Natural Rubber Vulcanizates
}

\author{
Yuzo TaKahashi* and Arthur V. Tobolsky \\ Department of Chemistry, Princeton University, Princeton, \\ New Jersey 08540, U.S.A.
}

(Received October 24, 1970)

\begin{abstract}
Chemical stress relaxation studies were carried out in air and in vacuo $(0.001 \mathrm{mmHg})$ on two natural rubber vulcanizates: one cured by dicumyl peroxide and the other by tetramethylthiuram disulfide. These are believed to produce carboncarbon cross-links and carbon-sulfur-carbon cross-links respectively.

Chemical stress relaxation in air showed that oxidative scissions along the main chains were major causes of stress decay for each vulcanizate. The stress decay curves for both vulcanizates were nearly the same in air.

Chemical stress decay in vacuo for the two samples was slower than that in air. The network with carbon-sulfur-carbon cross-links showed more rapid decay in vacuo than the network with carbon-carbon cross-links. Analysis of the effect of cross-link density on the decay curves in vacuo indicates that the cleavage was at the network junctures for the network with carbon-sulfur-carbon cross-links and the cleavage was along the main chains for the network with carbon-carbon closs-links.
\end{abstract}

KEY WORDS Chemorheology/Natural Rubber/Dicumyl Peroxide/

Tetramethylthiuram Disulfide / Vacuum / Air/Scission Reaction /

Chemical Bond Energy /

A. V. Tobolsky, et al. ${ }^{1}$ reported on oxidative degradation of vulcanized natural rubbers from chemorheological studies to the effect that random scission on main chains occurs preferentially regardless of the type of closs-links. However Berry and Watson ${ }^{2}$ reported that scissions occur at cross-links in preference. On the other hand, Horikx ${ }^{3}$ and Edwards ${ }^{4}$ observed from the swelling method that random scissions on main chains occur by oxidative degradation but, at the same time, scissions at cross-links should be considered.

The confusion arising from those observations has still not been settled.

All previous reports concerned with chemorheological studies of vulcanized natural rubbers have neglected thermal degradation in air. It is not possible to adequately discuss oxidative degradation without information on the thermal degration which will occur at the same rate and with the same temperature dependence both in air and in vacuo, since in chemorheological studies in air, thermal degradation can never be distinguished from oxidative degradation and errors

* The Central Research Laboratory of Hokkai Seikan Company, 839 Kanamuro, Iwatsuki, Saitama, Japan. will be made in analysing stress decay treated as oxidative degradation.

The authors suggest these confused reports about chemorheological studies on vulcanized natural rubbers are due to the fact that thermal degradation is considered to be negligibly small in air compared with oxidative degradation.

In this report, stress decay of vulcanized natural rubbers in air and in vacuo $(0.001 \mathrm{mmHg})$ were measured in relation to the cross-linking reagents, Dicumyl peroxide and Tetrathiuram disulfide, in order to clarify whether the type of scissions reactions were oxidative or thermal degradation, and to identify the weakest chemical bond in the rubber structure.

\section{EXPERIMENTAL}

\section{Materials}

The samples, R127-507 and R126-508, were cured natural rubbers supplied by the Goodyear Tire and Rubber Company. Details are as follows:

R127-507 (\# 507)

Smoked sheet natural rubber 100 cured 90

Dicumyl peroxide (Dicup) $2 \quad \min$ at

$\begin{array}{lll}\text { Phenyl- } \beta \text {-naphthylamine } & 1 & 300^{\circ} \mathrm{F} \\ & \left(149^{\circ} \mathrm{C}\right)\end{array}$ 
R127-508 (\#508)

$\begin{array}{lrc}\text { Smoked sheet natural rubber } & 100 & \begin{array}{c}\text { cured } 120 \\ \text { min at }\end{array} \\ \text { Zinc oxide } & 4 & 285^{\circ} \mathrm{F} \\ \text { Tetramethylthiuram disulfide } & 4 & \left(140^{\circ} \mathrm{C}\right) \\ \text { (TMTD) } & 1 & \\ \text { Phenyl- } \beta \text {-naphthylamine } & 1 & \end{array}$

By using both samples, \#507 and \#508, it was possible to compare the thermal stability of the chemical bonds at cross-links, carboncarbon and carbon-sulfur, because vulcanization with TMTD results in carbon-sulfurcarbon bonds whereas Dicup provides carboncarbon bonds at cross-links. In order to obtain samples with different cross-link densities, four additional samples were prepared by curing portions of the compositions of the samples \# 507 and \#508 described above, at $285^{\circ} \mathrm{F}\left(140^{\circ} \mathrm{C}\right)$ for 10 and $20 \mathrm{~min}$.

All samples used were subjected to thorough Soxhlet extraction in benzene for $48 \mathrm{hr}$ at $172^{\circ} \mathrm{F}$ $\left(72^{\circ} \mathrm{C}\right)$, and treated with acetone for $48 \mathrm{hr}$ at $159^{\circ} \mathrm{F}\left(64^{\circ} \mathrm{C}\right)$ after vulcanization to remove chemical residues. ${ }^{6}$

\section{Equipment and Procedure}

Stress relaxation measurements were conducted both in air and in high vacuum, using two different instruments. Measurements in air were made with the standard relaxation balance which has been previously described. ${ }^{7 \mathrm{a}}$ For measurements in vacuo a spring relaxometer developed by M. Shaw and A. V. Tobolsky, ${ }^{8}$ shown in Figure 1, was used.

Air is exhausted by vacuum pump and the degree checked with a Macleod vacuum gauge. The sample is extended to a certain ratio by the lower micrometer and then the limiting length is read by the upper micrometer in which the spring is detached from the stopper. The limiting length of the sensing spring is reduced to the stress. This stress is defined as $F(0)$ which means the stress at time $0 . \quad F(t)$, the stress at time $t$ in continuous stress relaxation is obtained by reading the limiting length of that spring at time $t$ keeping the lower micrometer at the initial position. In intermittent stress relaxation the sample is returned to zero stress with the lower micrometer after each reading is made.

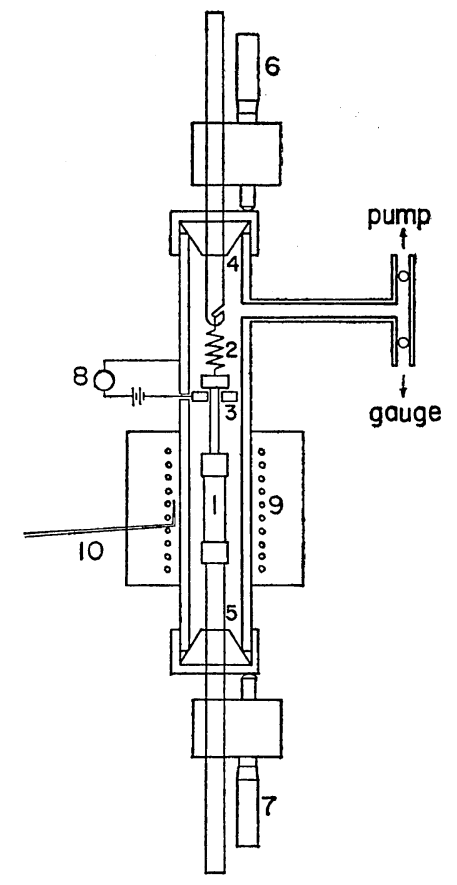

Figure 1. Spring relaxometer for stress decay measurements in vacuo: 1 , sample; 2 , sensing spring; 3 , stopper; 4 and 5 , teflon ferrule; 6 and 7, micrometer; 8, ampere meter; 9, heater and furnace; 10 , thermocouple.

Cross-link densities $N(0)$ and $N(t)$ at time 0 and $t$ are calculated with $F(0)$ and $F(t)$ using the following equations

$$
\begin{aligned}
& F(0)=N(0) R T\left(\alpha^{2}-\frac{1}{\alpha}\right) \\
& F(t)=N(t) R T\left(\alpha^{2}-\frac{1}{\alpha}\right)
\end{aligned}
$$

where $\alpha$ is extension ratio, $R$ is gas constant and $T$ is temperature $\left({ }^{\circ} \mathrm{K}\right)$

The samples for measurements in vacuo were conditioned in vacuo at $50^{\circ} \mathrm{C}$ below the test temperature for $16 \mathrm{hr}$ before each run to eliminate the oxygen molecules in the sample. In both air and vacuum measurements, the temperature was raised to the test temperature and held for one hour. The sample was then extended, usually with $\alpha=1.1-1.2$, and the taking of stress vs. time measurements was commenced. 


\section{RESULTS AND DISCUSSION}

\section{Stress Decay Curve}

Stress decay in continuous stress relaxation in in air and in vacuo are shown in the form $F_{\mathrm{c}}(t) / F_{\mathrm{c}}(0)$ (relative stress) $v s$. time in Figures 2 and 3. The stress decays at a higher rate in air than in vacuo for both samples, \#507 and \#508. In vacuo, stress decay is negligibly small compared with that in air for \#507 but for \#508, the rate of stress decay is comparatively higher.
Generally, all stress decay curves are considered to include stress decay caused by physical stress relaxation. Physical stress relaxation originating from entanglements of main chains or secondary bonds is presumed to occur with the same velocity at the same temperature and the same temperature dependence both in air and in vacuo. However, in practice, physical stress relaxation can never be distinguished from chemical stress relaxation at high temperatures. In this report, all stress decay which has a linear relation between $\log F_{\mathrm{c}}(t) / F_{\mathrm{c}}(0)$ and time is assumed to be due to

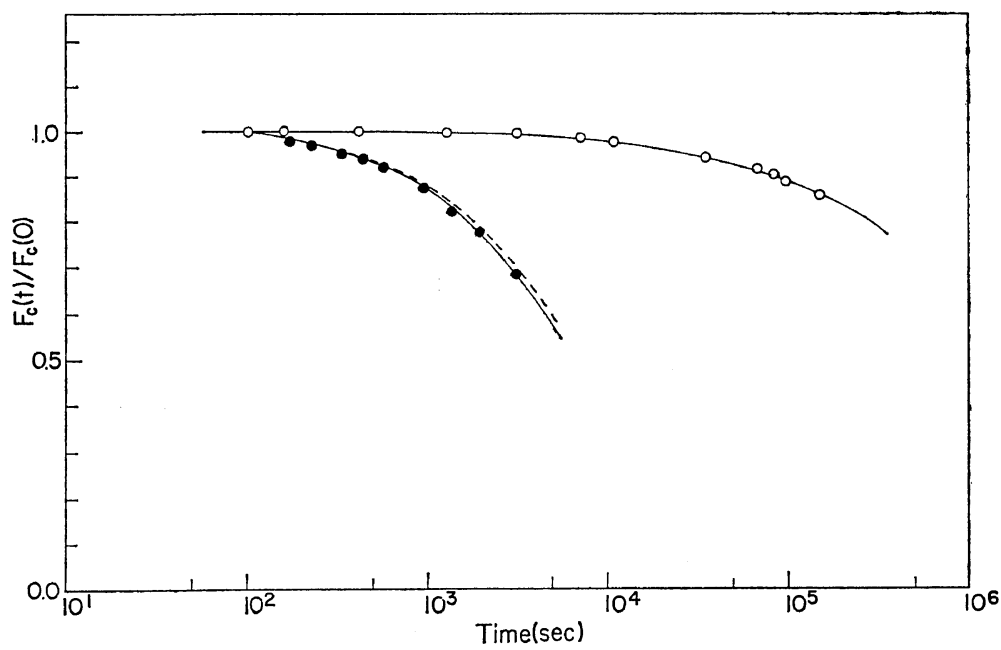

Figure 2. $\quad F_{\mathrm{c}}(t) / F_{\mathrm{c}}(0)$ vs. time for $\mathrm{R} 127-507$ (Dicup cure) at $200^{\circ} \mathrm{C}$ : $\mathrm{O}$, in vacuo; , in air; $-\cdots, 1+\left\{\left[F_{\mathrm{c}}(t) / F_{\mathrm{c}}(0)\right]_{\mathrm{air}}-\left[F_{\mathrm{c}}(t) / F_{\mathrm{c}}(0)\right]_{\text {vacuum }}\right\}$.

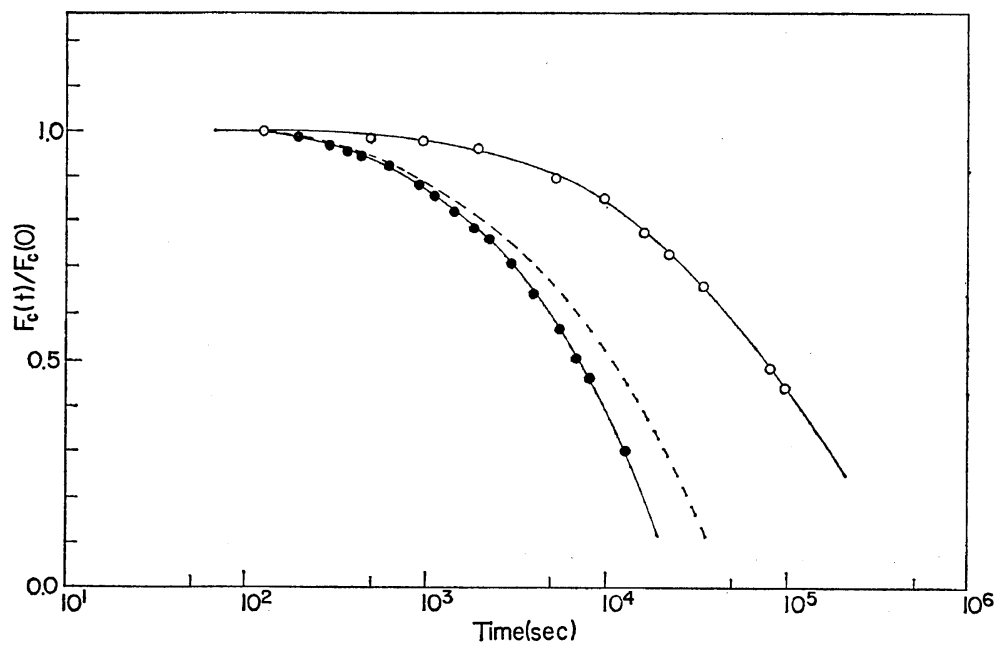

Figure 3. $F_{\mathrm{c}}(t) / F_{\mathrm{c}}(0) v s$. time for R127-508 (TMTD cure) at $200^{\circ} \mathrm{C}$ : $\bigcirc$, in vacuo; $\bullet$, in air; ,$-- 1+\left\{\left[F_{\mathrm{c}}(t) / F_{\mathrm{c}}(0)\right]_{\mathrm{air}}-\left[F_{\mathrm{c}}(t) / F_{\mathrm{c}}(0)\right]_{\text {vacuum }}\right\}$. 
chemical stress relaxation according to Tobolsky's theory $^{7 \mathrm{~b}}$.

Plots of $\log F_{\mathrm{c}}(t) / F_{\mathrm{c}}(0)$ vs. time are shown in Figures 4-7. Linear relationships are seen for \# 507 and \# 508 in air over the longer-time region, but over the shorter-time region in vacuo. In vacuuo, the rare of stress decay decreases in longer-time region deviating from a linear relation between $\log F_{\mathrm{c}}(t) / F_{\mathrm{c}}(0)$ and time.

The authors, ${ }^{6}$ Flory, ${ }^{10}$ and others ${ }^{11,12}$, reported that cross-linking in the stretched samples decreases the rate of stress decay depending on the reaction rate of cross-linking. According to these reports, the deviation from linearity in vacuo is considered to be caused by the crosslinking reaction in the sample within the running of the stress decay measurements. The crosslinking reaction is known from the difference in the relative stress of intermittent stress relaxation $F_{\mathrm{i}}(t) / F_{\mathrm{i}}(0)$ and $F_{\mathrm{c}}(t) / F_{\mathrm{c}}(0)$ using the following well-known equations ${ }^{7 \mathrm{~b}}$ and the results are shown in Figure 8.

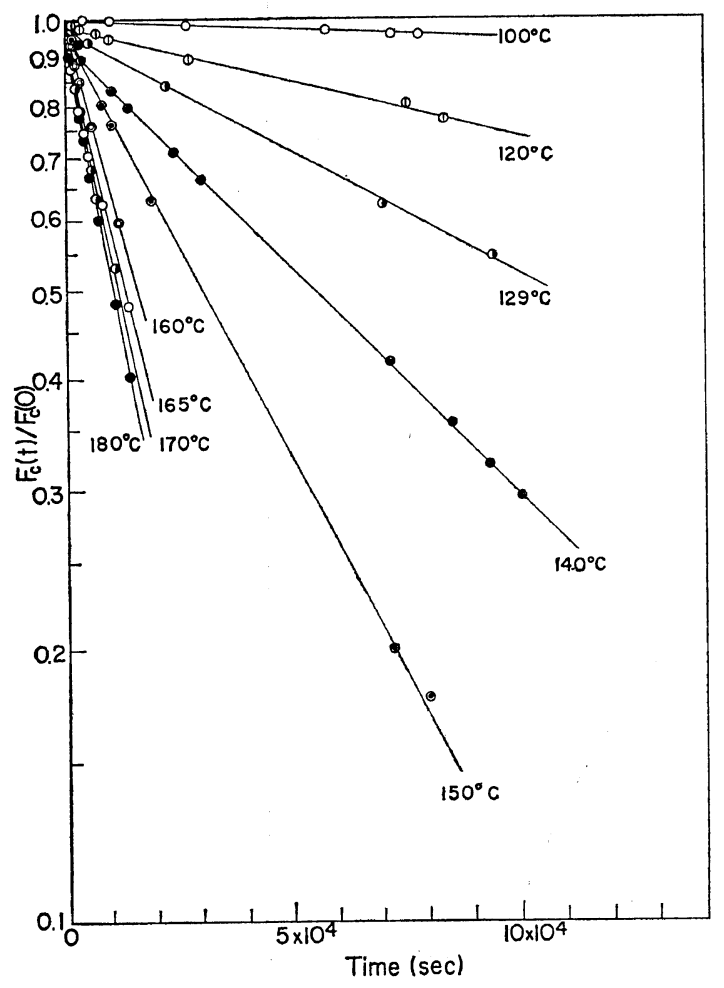

Figure 4. $\log F_{\mathrm{c}}(t) / F_{\mathrm{c}}(0)$ vs. time for R127-507 (Dicup cure) in air.

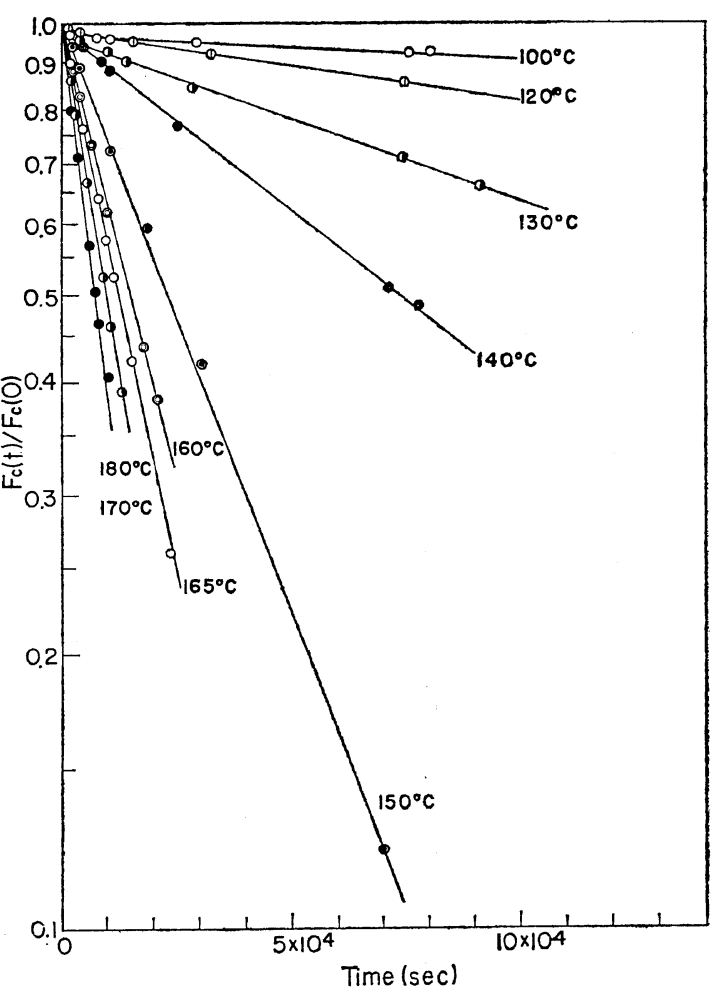

Figure 5. $\log F_{\mathrm{c}}(\boldsymbol{t}) / F_{\mathrm{c}}(0)$ vs. time for $\mathrm{R} 127-508$ (TMTD cure) in air.

$$
\begin{aligned}
\frac{F_{\mathrm{i}}(t)}{F_{\mathrm{i}}(0)} & =\frac{N(0)-Q(t)+\Delta N(t)}{N(0)} \\
\frac{F_{\mathrm{c}}(t)}{F_{\mathrm{c}}(0)} & =\frac{N(0)-Q(t)}{N(0)} \\
\frac{F_{\mathrm{i}}(t)}{F_{\mathrm{i}}(0)}-\frac{F_{\mathrm{c}}(t)}{F_{\mathrm{c}}(0)} & =\frac{\Delta N(t)}{N(0)}
\end{aligned}
$$

where $Q(t)$ is the cross-link density decreased by the scission reaction and $\Delta N(t)$ is that increased by the closs-linking reaction

The closs-linking reaction in \#508 is more active than in $\# 507$ and this is due to the fact that the linearity of $\# 508$ vanishes more quickly than in the case of $\# 507$.

These cross-linking reactions may be as follows, in light of measurement conditions in vacuo.

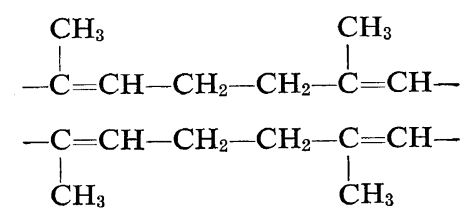

Polymer J., Vol. 2, No. 4, 1971 
Chemorheological Study on Natural Rubber Vulcanizates

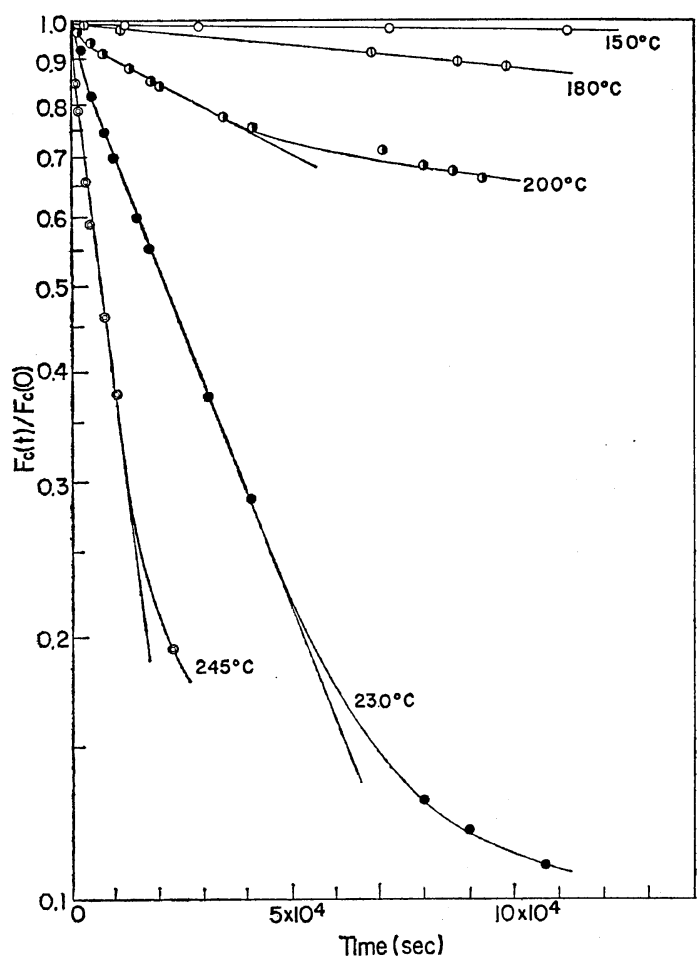

Figure 6. $\log F_{\mathrm{c}}(t) / F_{\mathrm{c}}(0)$ vs. time for $\mathrm{R} 127-507$ (Dicup cure) in vacuo.

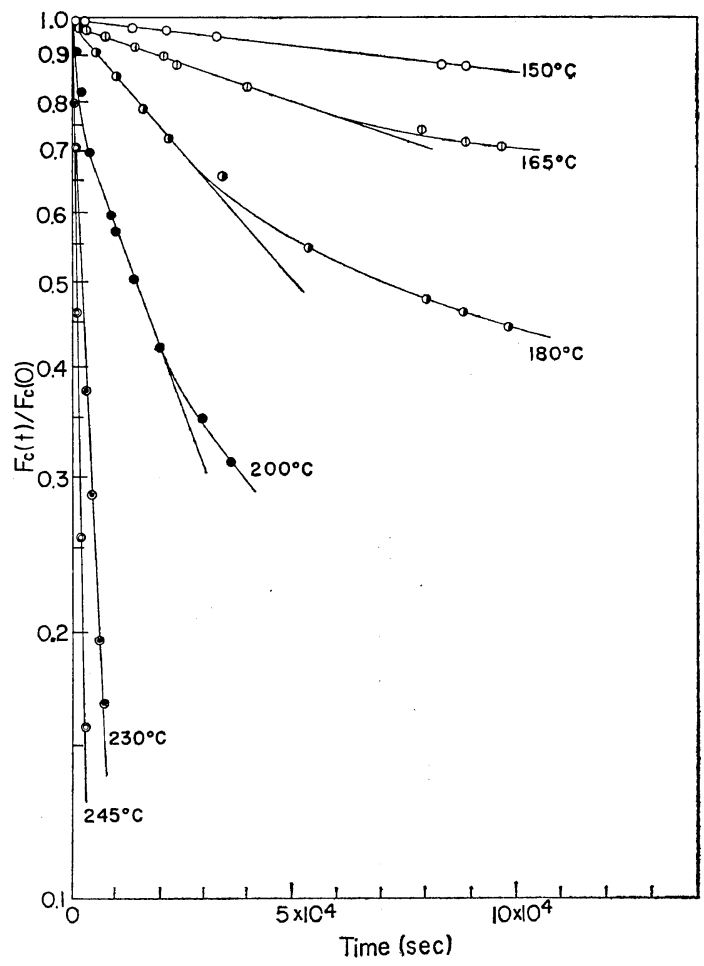

Figure 7. $\log F_{\mathrm{c}}(\boldsymbol{t}) / \boldsymbol{F}_{\mathrm{c}}(\mathbf{0})$ vs. time for $\mathrm{R} 127-508$ (TMTD cure) in vacuo.

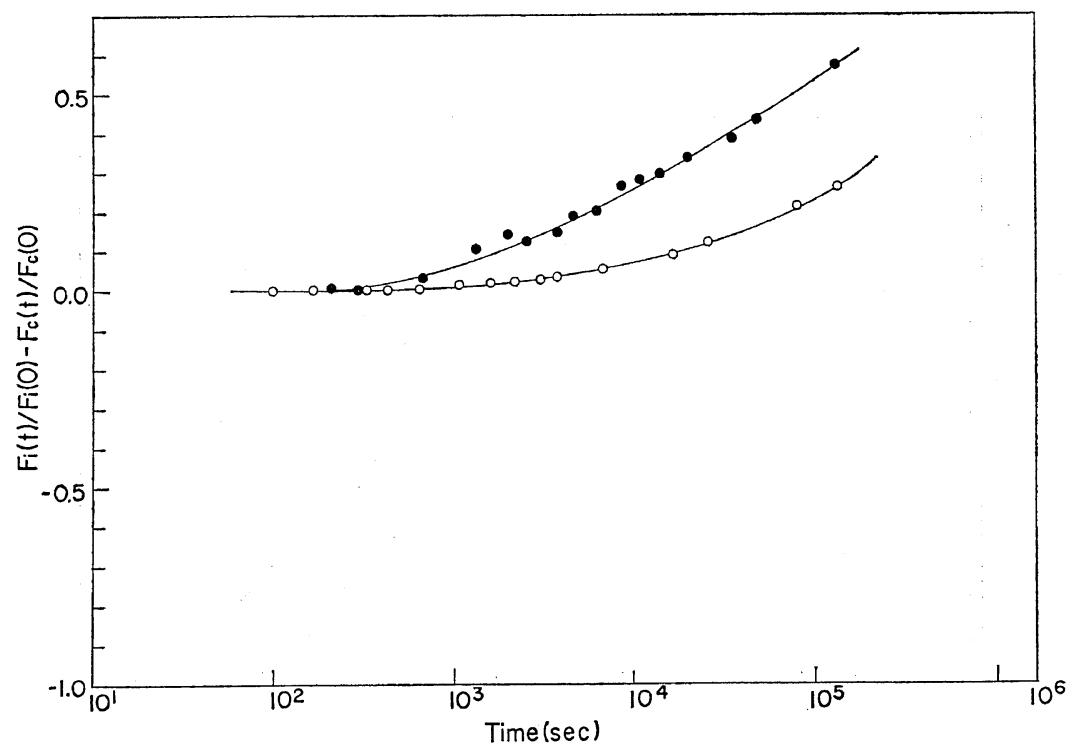

Figure 8. $\left[F_{\mathrm{i}}(t) / F_{\mathrm{i}}(0)-F_{\mathrm{c}}(t) / F_{\mathrm{c}}(0)\right]$ vs. time for both samples at $200^{\circ} \mathrm{C}$ in vacuo: $\bigcirc, \mathrm{R} 127-507$ (Dicup cure); $\bullet$, R127-508 (TMTD cure). 


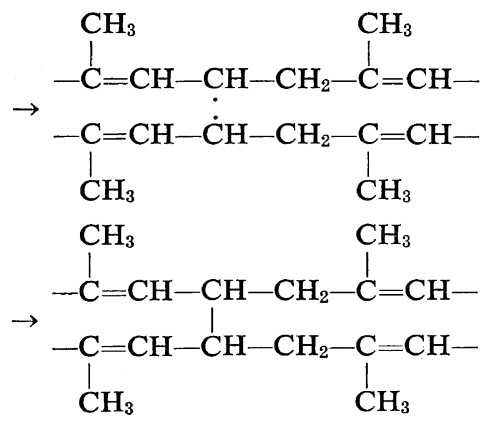

\section{Scission Reaction}

$N(0)$ (initial cross-link density) dependences of $F_{\mathrm{c}}(t) / F_{\mathrm{c}}(0)$ are shown in Figures 9-12. In air, both samples, \#507 and \#508, show $N(0)$ dependence apparently indicating that scissions occur preferentially at random on main chains, in accordance with Tobolsky's theory. ${ }^{7 \mathrm{~b}}$ In vacuo, \#507 shows $N(0)$ dependence as in air but \#508 does not. Scissions in \#508 in vacuo occur preferentially at cross-links not at main chains.

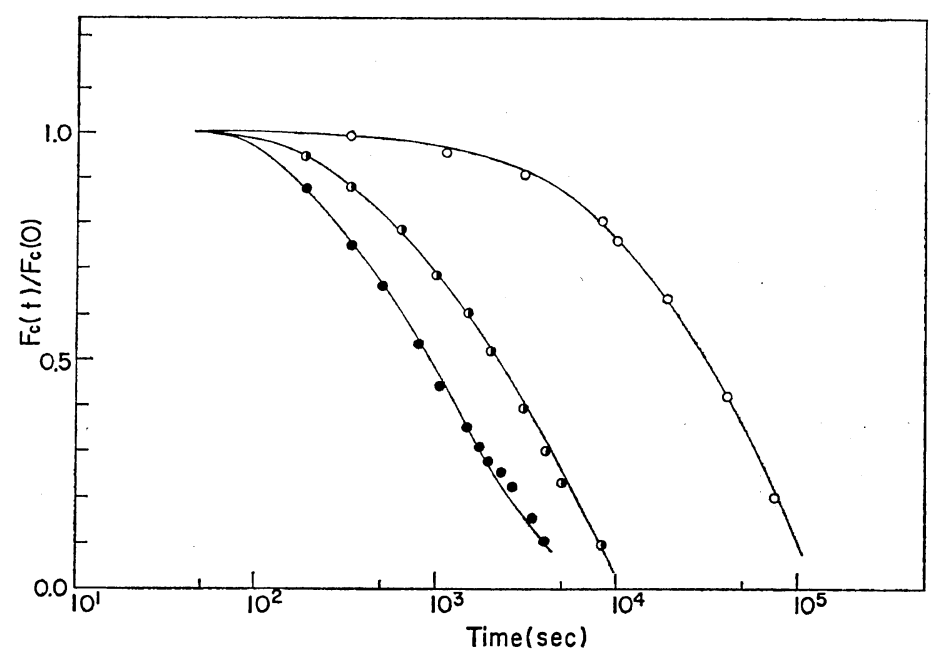

Figure 9. $N(0)$ dependence of $F_{\mathrm{c}}(t) / F_{\mathrm{c}}(0)$ for $\mathrm{R} 127-507$ (Dicup cure) at $150^{\circ} \mathrm{C}$ in air: $\mathrm{O}$, $N(0)=11.0 \times 10^{-5} \mathrm{~mol} / \mathrm{cc} ; O, N(0)=2.5 \times 10^{-5} \mathrm{~mol} / \mathrm{cc} ; \quad$, $N(0)=0.73 \times 10^{-5} \mathrm{~mol} / \mathrm{cc}$.

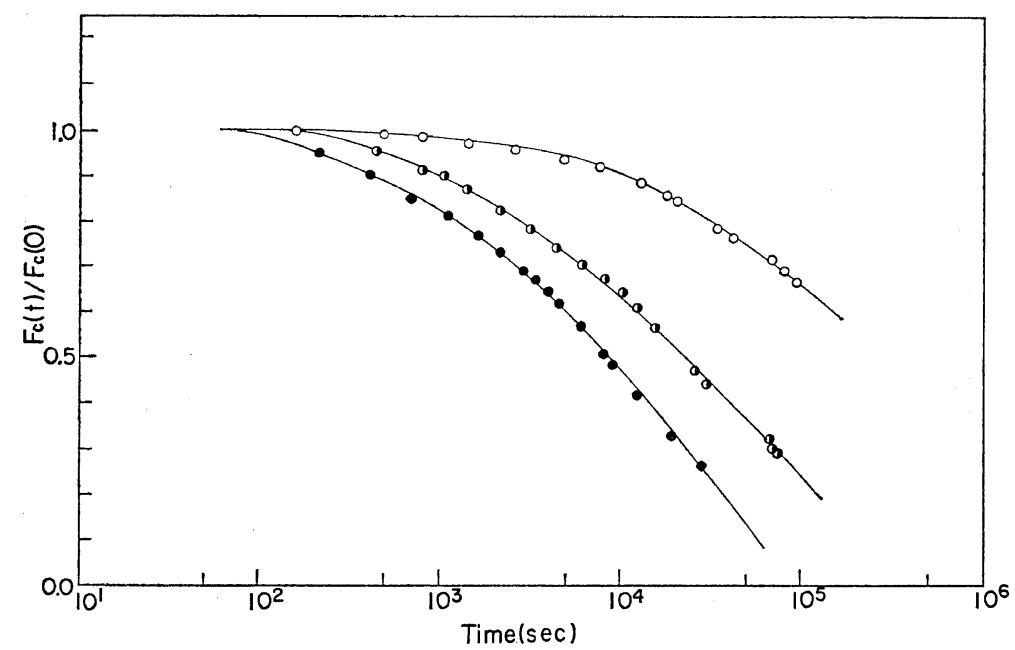

Figure 10. $N(0)$ dependence of $F_{\mathrm{c}}(t) / F_{\mathrm{c}}(0)$ for $\mathrm{R} 127-507$ (Dicupe cure) at $200^{\circ} \mathrm{C}$ in vacuo: O, $N(0)=15.9 \times 10^{-5} \mathrm{~mol} / \mathrm{cc} ; N(0)=5.8 \times 10^{-5} \mathrm{~mol} / \mathrm{cc}, \quad, N(0)=3.9 \times 10^{-5} \mathrm{~mol} / \mathrm{cc}$. 


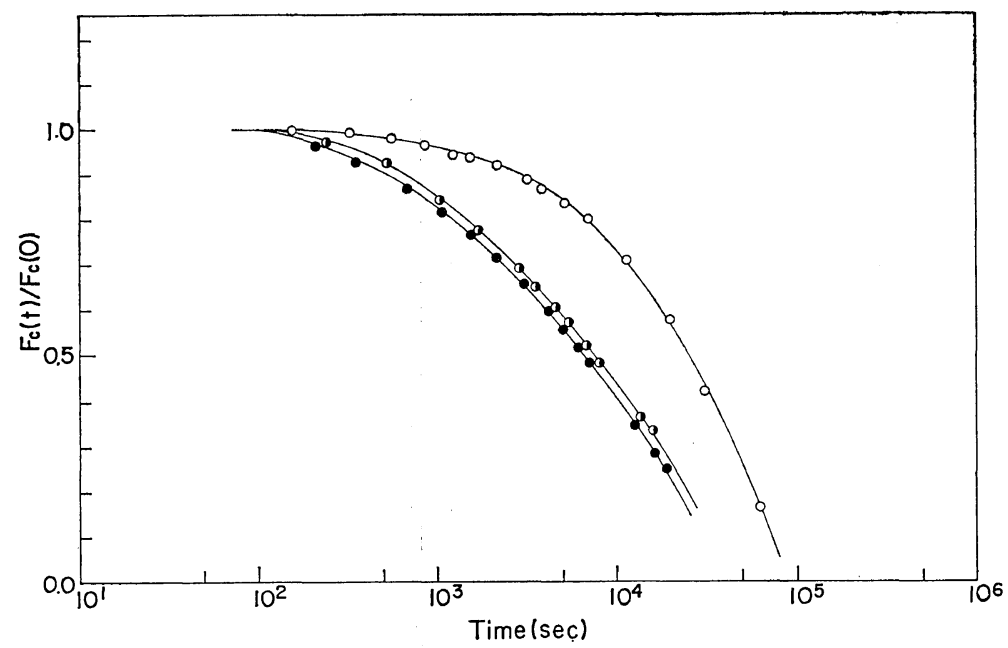

Figure 11. $N(0)$ dependence of $F_{\mathrm{c}}(t) / F_{\mathrm{c}}(0)$ for R127-508 (TMTD cure) at $150^{\circ} \mathrm{C}$ in air: $\bigcirc, N(0)=20.7 \times 10^{-5} \mathrm{~mol} / \mathrm{cc} ; \quad N(0)=7.4 \times 10^{-5} \mathrm{~mol} / \mathrm{cc} ; \bullet, N(0)=7.1 \times 10^{-5} \mathrm{~mol} / \mathrm{cc}$.

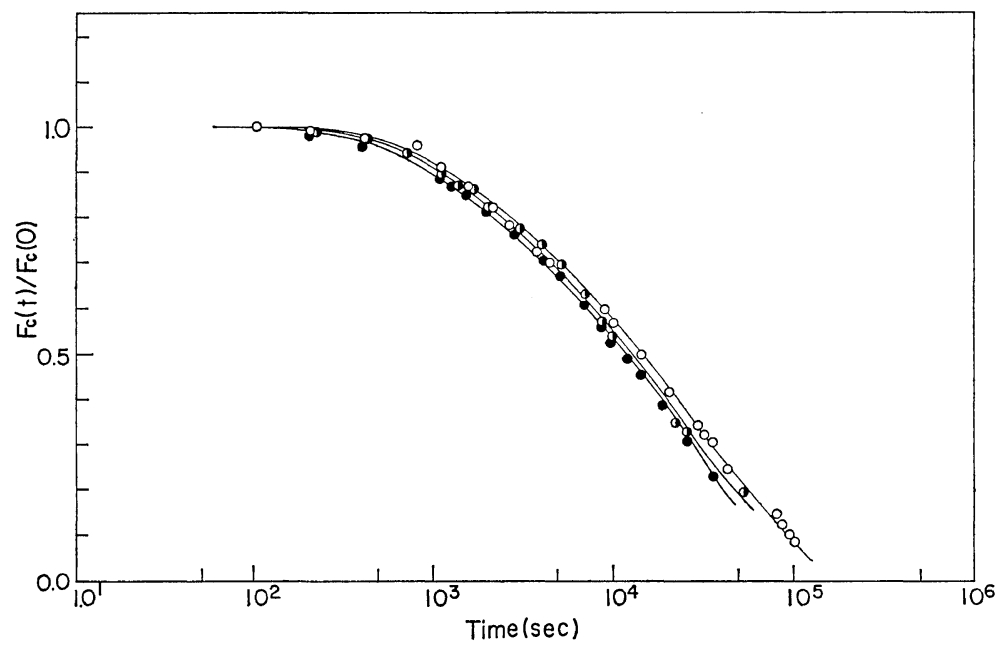

Figure 12. $N(0)$ dependence of $F_{\mathrm{c}}(t) / F_{\mathrm{c}}(0)$ for R127-508 (TMTD cure) at $200^{\circ} \mathrm{C}$ in vacuo: $\bigcirc, N(0)=17.5 \times 10^{-5} \mathrm{~mol} \mathrm{cc} ; N(0)=8.4 \times 10^{-5} \mathrm{~mol} / \mathrm{cc} ; \quad, N(0)=7.4 \times 10^{-5} \mathrm{~mol} / \mathrm{cc}$.

Thermal degradation was seen to decay the stress at a comparatively high rate for $\# 508$ even in vacuo, as shown in Figure 3. It is reasonable to consider that thermal degradation (leads scissions at cross-links) decay the stress at the same rate in air as in vacuo, in addition to the stress decay by oxidative degradation (leads random scissions on main chains). From these facts, it is concluded that random scissions on main chains mainly occur from oxidative degradation for
\#508 in air but, in addition to this, scissions at cross-links occur also through thermal degradation at a certain ratio. This conclusion agrees with that reported by Horikx ${ }^{3}$ and Edwards ${ }^{4}$ except for the considerations associated with thermal degradation.

In order to ascertain the stress decay curves caused only by oxidative degradation, the difference between the relative stress in air and that in vacuo can be used as shown in the following: 
Relative stress in air

$$
\begin{aligned}
\left(\frac{F_{\mathrm{c}}(t)}{F_{\mathrm{c}}(0)}\right)_{\mathrm{air}} & =\frac{N(0)-Q(t)_{\mathrm{air}}}{N(0)} \\
& =\frac{N(0)-Q(t)_{\text {oxid }}-Q(t)_{\text {therm }}}{N(0)} \\
& =\frac{N(0)-Q(t)_{\text {oxid }}}{N(0)}+\frac{N(0)-Q(t)_{\text {therm }}}{N(0)}-1 \\
& =\left(\frac{F_{\mathrm{c}}(t)}{F_{\mathrm{c}}(0)}\right)_{\text {oxid }}+\left(\frac{F_{\mathrm{c}}(t)}{F_{\mathrm{c}}(0)}\right)_{\text {therm }}-1
\end{aligned}
$$

Relative stress in vacuo

$$
\left(\frac{F_{\mathrm{c}}(t)}{F_{\mathrm{c}}(0)}\right)_{\text {vacuum }}=\left(\frac{F_{\mathrm{c}}(t)}{F_{\mathrm{c}}(0)}\right)_{\text {therm }}
$$

Relative stress only by oxidative degradation

$$
\left(\frac{F_{\mathrm{c}}(t)}{F_{\mathrm{c}}(0)}\right)_{\text {oxid }}=1+\left\{\left(\frac{F_{\mathrm{c}}(t)}{F_{\mathrm{c}}(0)}\right)_{\text {air }}-\left(\frac{F_{\mathrm{c}}(t)}{F_{\mathrm{c}}(0)}\right)_{\text {vacuum }}\right\}
$$

where subscripts "vacuum", "air" mean the measurement conditions in vacuo or in air and "therm", "oxid" mean the type of degradation reaction, thermal or oxidative degradation.

This is shown in Figures 2 and 3 with dotted curves.

The larger contribution of thermal degradation in stress decay curves measured in air for $\# 508$ is indicated, in comparison with \#507. It is apparent that thermal degradation in air cannot be ignored both from the above facts and from the analysis of the stress decay curves measured in vacuo.

The gradients of lines in Figures $4-7$ are the rate constants of the cross-link cleavage reaction $K$, expressed by Arrhenius' equation as follows

$$
K=A \exp \left(-\frac{E}{R T}\right)
$$

where $E$ is the apparent activation energy (kcal/ mol) for cross-link cleavage reaction, $R$ is gas constant and $T$ is the measurement temperature $\left({ }^{\circ} \mathrm{K}\right)$

Temperature dependence of $K$ is plotted as $\log K$ vs. $1 / T\left({ }^{\circ} \mathrm{K}\right)$ in Figure 13. The value of $E$ for random scission on main chains in air is about $53 \mathrm{kcal} / \mathrm{mol}$ for both samples. This value is larger than that reported by previous workers. $E$ for scissions at cross-links by thermal degradation in vacuo for $\$ 508$ is $55 \mathrm{kcal} / \mathrm{mol}$ but for $\# 507$, $E$ for scissions on main chains by thermal degra-

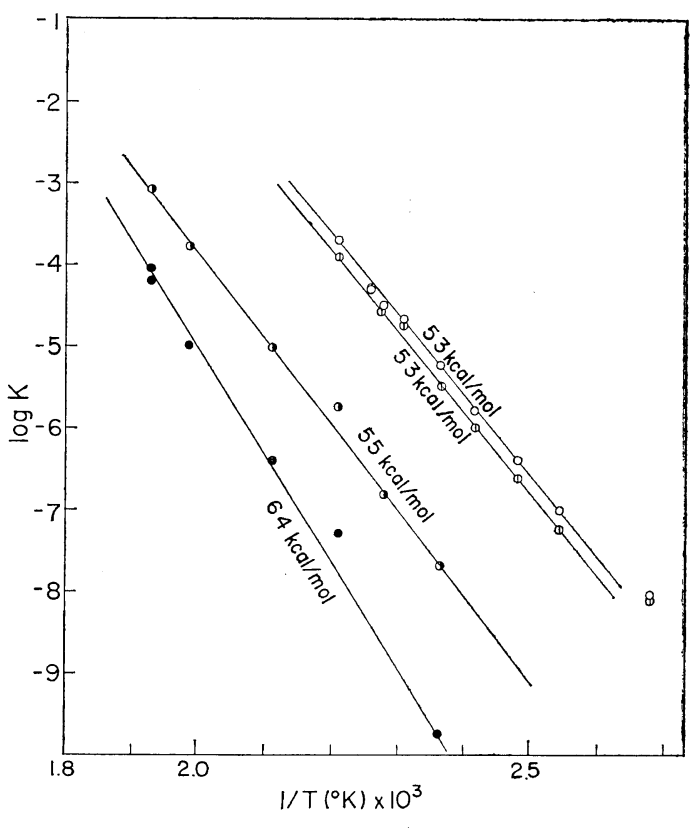

Figure 13. $\log K$ vs. $1 / T\left({ }^{\circ} \mathrm{K}\right)$ and the apparent activation energy of scission reactions: $O, \mathrm{R} 127-$ 507 (Dicup cure) in air; - R127-507 (Dicup cure) in vacum; (1), R127-508 (TMTD cure) in air; $)$, R127-508 (TMTD cure) in vacuo.

dation is $64 \mathrm{kcal} / \mathrm{mol}$, which is higher than for \# 508. The value of $K$ is slightly larger for \# 507 than for \#508 in air. The value of $K$ may indicate the structure dependence of the cleavage reaction. This structure dependence seems to be due to the fact that, in the case of $\# 507$ cured by Dicup, the main chains are combined directly with covalent bonding between carbon atoms on the main chains. This suggests the existence of a strong restriction on mobility of main chains near the cross-links because the free volume near the cross-links is small and the entropy must be decreased with the increase of the elastic internal energy near the cross-links. On the other hand, in the case of \#508 cured by TMTD, the main chains are combined 'with each other in carbon-sulfur-carbon bonding with an extra molecular sulfur. This gives larger mobility to main chains near the cross-links with small elastic internal energy.

In vacuo, the value of $K$ for $\# 508$ is higher than for \#507 by the factor $10-20$. This may suggest that the cleavage reaction depends on 
the chemical bond energy. Generally, the value of $K$ in air exceeds that of $K$ in vacuo by the factor 100-1000. This means that oxidative degradation occurs more readily than thermal degradation. All of these results are reasonable on the basis of the bond energy.

Ossefort ${ }^{13}$ reported that the bond energy of carbon-carbon and carbon-sulfur in the rubber structure are 63 and $55 \mathrm{kcal} / \mathrm{mol}$, respectively. These bond energies should be compared with $E$ for thermal degradation measured in vacuo, not for oxidative degradation in air. The value of $E$ for $\# 507$, mainly due to random scissions of carbon-carbon bonds on main chains, is $64 \mathrm{kcal} / \mathrm{mol}$ and equal to the value of the carbon-carbon bond energy. The value of $E$ for \# 508, due to scissions of carbon-surfur bond at cross-links, is $55 \mathrm{kcal} / \mathrm{mol}$ and equal to the value of carbon-sulfur bond energy. These facts support our deduction concerning the cleavage reaction in vacuo, by considering the structure of \#507 and \#508 as follows<smiles>CCCC=C(C)CCCCC(C)(C)SC(C)(C)CCCC(C)(C)C(C)(C)CCCCC</smiles>

In the case of $\# 507$, the weakest bond is the carbon-carbon bond and the scissions occur on main chains and at cross-links. But the molecular weight of main chains between cross-links calculated from $N(0)$ is the order of $10^{4}-10^{5}$. This shows that the number of carbon-carbon bonds on main chains are larger than the number of cross-links by the factor of $10^{3}-10^{4}$. This is the reason why the probability of scissions on main chains is greater in comparison with that at cross-links and random scissions on main chains are chiefly observed.

In the case of $\# 508$, the weakest bond is the carbon-sulfur bond and the bond energy is $55 \mathrm{kcal} / \mathrm{mol}$. Therefore, carbon-sulfur bonds break more easily than others. This results in scissions on cross-links mainly being observed for \#508 in vacuo. But the same number of carbon-carbon bonds on main chains should be kept in \#508 as in \#507 and this means that the random scissions on main chains may occur at the same rate and at the same temperature dependence as in $\$ 507$, in addition to scissions of carbon-sulfur bonds. In other words, the value of $K$ for $\# 508$ includes the value by scission reaction on carbon-carbon bonds on main chains. The value of $K$ by scission reaction at carbon-sulfur bonds only is thus the difference of both $K$ 's for $\# 508$ and for $\# 507$, as shown in Figure 14. $E$ of scission of carbonsulfur bonds calculated from Figure 14 is equal to that of oxidative degradation in air. It is resonable to have infered in the previous section that, in air, random scissions on main chains by oxidative degradation and scissions at crosslinks by thermal degradation may occur simultaneously for $\# 508$, considering the value of $E$. Moreover, the closeness of the values of $E$ and bound energy of the carbon-carbon bond and the carbon-sulfur bond suggests that even in

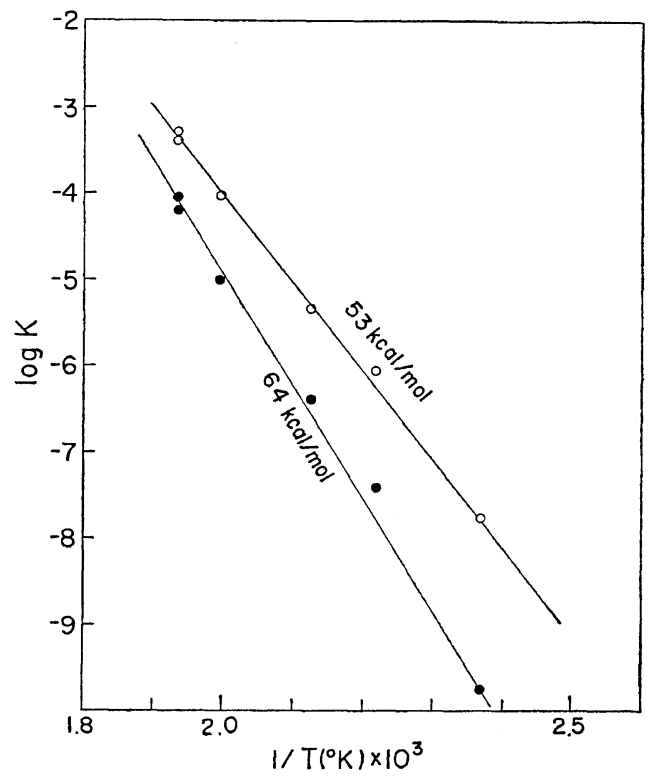

Figure 14. $\log K$ vs. $1 / T\left({ }^{\circ} \mathrm{K}\right)$ and the apparent activation energy of scission reactions in vacuo: $\bigcirc$, scission of carbon-sulfur bond; $\bullet$, scission of carbon-carbon bond. 
vacuo, physical relaxation may be negligibly small compared with chemical relaxation, and this goes without saying in air.

The mechanism of scission reaction may be simple for each degradation for both samples, \#507 and \#508, in vacuo taking into consideration the equality of $E$ and each bond energy.

It is said that the electron density of the carbon-carbon bond inserted between two double bonds is weaker than others because of their electronegativity. Therefore, on heating, this bond breaks resulting in random scissions on the main chains.<smiles>CC=CC(C)=CCC(C)=C(C)C</smiles>

For \#508 the weakest bond, the carbon-sulfur bond, may break directly as<smiles>C=CC(C)(C)CCCC(C)(C)SC(C)(C)CCCCC(C)(C)SC(C)(C)CCCCC(=C)C</smiles>

The above results may be shown as follows.

Thermal degra- Oxidative degradation dation

\begin{tabular}{|c|c|c|}
\hline $\begin{array}{l}\text { \#507 } \\
\text { Dicup } \\
\text { cured }\end{array}$ & $\begin{array}{l}\text { Random scission } \\
\text { on carbon- } \\
\text { carbon bonds }\end{array}$ & $\begin{array}{l}\text { Random scission } \\
\text { on carbon- } \\
\text { carbon bonds }\end{array}$ \\
\hline $\begin{array}{l}508 \\
\text { TMTD }\end{array}$ & $\begin{array}{l}\text { Scission at cross- } \\
\text { links of carbon- } \\
\text { sulfur bonds } \\
\text { (main) }\end{array}$ & $\begin{array}{l}\text { Random scission } \\
\text { on carbon- } \\
\text { carbon bonds } \\
\text { (main) }\end{array}$ \\
\hline & $\begin{array}{l}\text { Random scission } \\
\text { on carbon- } \\
\text { carbon bonds }\end{array}$ & Scission at cross- \\
\hline
\end{tabular}

\section{CONCLUSION}

Natural rubber vulcanized in two different ways, using Dicup and TMTD, were investigated for oxidative and thermal stability, both under atmospheric conditions and under vacuum $(0.001 \mathrm{mmHg})$ in the higher temperature ranges $\left(>100^{\circ} \mathrm{C}\right)$ by means of chemical-stress relaxation measurements.

In air, the cleavage reactions of both $\# 507$ (Dicup cured) and \#508 (TMTD cured) mainly occur along the network chains, but there is small difference in the magnitudes of the rate constants of the cleavage reaction depending on the chemical structure at the cross-links rather than along the network chains.

The rate of cleavage reaction of \#508 in vacuo is slower than that in air by a factor of approximately 100 while the cleavage reaction of $\# 507$ in vacuo is slower than that in air by a factor of 1000 or more. Therefore, the effects of oxygen in air on the chemical stress relaxation, which ruptured the rubber structure and caused the decay of stress, are very important. In vacuo, the thermal stability of the monosulfide cross-linkage (such as \#508) is less than that of both the carbon-carbon closs-linkage (such as \#507) and the main chains in natural rubber, and thermal stability seemed to depend only on the bond energy, easier to break for weaker bonds such as carbon-sulfur than in the case of carbon-carbon.

The apparent activation energy for the oxidative scissions in air is found to be $53 \mathrm{kcal} / \mathrm{mol}$ for both \#507 and \#508. It is 63 and $55 \mathrm{kcal} /$ mol respectively for \#507 and \#508 in vacuo (0.001 $\mathrm{mmHg})$.

\section{REFERENCES}

1. A. V. Tobolsky, I. S. Prettyman, and J.H. Dillon, J. Appl. Phys., 15, 380 (1944).

2. J. P. Berry and W. F. Watson, J. Polym. Sci., 18, 201 (1955); 25, 497 (1957).

3. M. M. Horikx, J. Polym. Sci., 19, 445 (1956).

4. D. C. Edwards, Kaut. Gummi, Kunst., 17, 633 (1964).

5. L. Bateman, "Chemistry and Physics of Rubberlike Substances" John Wiley and Sons, Inc., New York N.I., 1963, p 729.

6. J. R. Dunn, J. Appl. Polym. Sci., 7, 1543 


\section{Chemorheological Study on Natural Rubber Vulcanizates}

(1963).

7. A. V. Tobolsky, "Properties and Structure of Polymers" John Wiley and Sons, Inc., New York N.Y., 1960, (a) p 143 and (b) 233.

8. M. T. Shaw and A. V. Tobolsky, ONR Technical Report, Office of Naval Research, December 1968, No. 111, Task No. NR 056-377.
9. K. Murakami, T. Kusano, S. Naganuma and Y. Takahashi, Bull. Chem. Res. Inst. NonAqueous Solutions, Tohoku Univ. 19, 243 (1969).

10. P. J. Flory, Trans. Faraday Soc., 56, 722 (1960).

11. J. Scanlan, Tran. Fasaday Soc., 57, 839 (1961).

12. D. K. Thomas, Polymer, 7, 125 (1966).

13. Z. T. Ossefort, Rubber World, 140, 69 (1959). 